\title{
Knowledge Management and its Effects on Financial Performance: Evidence from Dangote Flour Mills, Ilorin
}

http://doi.org/10.21272/fmir.4(2).34-42.2020.

Bolatito Amudat Brimah, ORCID: https://orcid.org/0000-0003-3272-0304

$\mathrm{PhD}$, Department of Business Administration, Faculty of Management Sciences, Al-Hikmah University, Ilorin, Nigeria

Wahid Damilola Olanipekun, ORCID: https://orcid.org/0000-0002-9651-6655

$\mathrm{PhD}$, Department of Management and Accounting, College of Management and Social Sciences, Summit University, Offa, Nigeria

Ayodeji Gbenga Bamidele, ORCID: https://orcid.org/0000-0003-1114-0714

$\mathrm{PhD}$, Department of Business \& Entrepreneurship, School of Business and Governance, Kwara State University, Malete.

Musa Ibrahim, ORCID: https://orcid.org/0000-0001-9781-039

Department of Business Administration, Faculty of Management Sciences, Al-Hikmah University, Ilorin, Nigeria

\begin{abstract}
This paper summarizes the arguments and counterarguments within the scientific discussion on the issue of knowledge management and their impact on the financial performance of economic entities. It is determined that despite the key role of knowledge both for the development of the country (which in the 21 st century is based mainly on knowledge) and to increase the value of the company, today companies do not fully use arrays of knowledge and data, which forms barriers to increase competitiveness in the strategic perspective. The main purpose of this study is to assess the impact of knowledge management on the financial performance of companies. Data for the study were obtained from a primary source based on a structured questionnaire with which Dangote Flourmills staff worked. The methodology of the work is a software product for statistical data processing - STATA 11, while the data analysis was performed on the basis of regression analysis, which was used to test hypotheses at the level of $5 \%$ significance. The analysis of the data confirmed the significance of the impact of all indicators of knowledge management on the financial performance of the economic entity. The results theoretically confirmed and empirically proved that strategic leadership, organizational culture, information and communication technologies, effective human resource management practices have a significant impact on financial performance. This study concludes that knowledge management has a significant impact on the financial performance of businesses. The paper states that knowledge management activities help to focus the company's management on the accumulation, storage and use of knowledge to solve problems, dynamic learning, strategic planning and making sound financial and economic decisions. The authors have formed the following recommendations: assistance from the management of the company to exchange knowledge, training and professional development; introduction of the latest digital technologies to improve communication and management mechanisms, based on the specifics, features and needs of companies; ensuring and developing a corporate culture that allows you to balance and coordinate the actions of management policy.
\end{abstract}

Keywords: knowledge management, human resources, strategic leadership, organizational culture, financial results of the company.

\section{JEL Classification: G32.}

\section{(i)}

This work is licensed under a Creative Commons Attribution 4.0 International License

Cite as: Brimah, B. A., Olanipekun, W. D., Bamidele, A. G., Ibrahim, M. (2020). Knowledge Management and its Effects on Financial Performance: Evidence from Dangote Flour Mills, Ilorin. Financial Markets, Institutions and Risks, 4(2), 34-42. http://doi.org/10.21272/fmir.4(2).34-42.2020.

(C) The Authors, 2020. This article is published with open access at Sumy State University. 


\section{Introduction}

The success and failure of every business is in one way or the other attached to the environment where it operates because of the highly characterize uncertainty that is attached to this environment irrespective of it goals and objectives especially in this current aggressive, exceptionally competitive, and complex business environments. As organizations are continually looking for means of developing novel (new) and appropriate (relevant) ideas, breaking down of prior assumptions and making new connections for new ideas. Thus, emphasis is placed on creativity by organizations and this entails changing the old process, introducing new ways and new products hence accelerating the pace of change in organizations and the society in general. Similarly, organizations in pursuance of ensuring that ideas see the light of the day embrace innovation practices (Bamidele. 2019)

However, since innovation has become the prime importance to any company or organization for performing well, knowledge has become one of the most vital assets that guaranteed the survival of firms in the fiercely competitive business environment. The emergence of knowledge-based economy has made it a strategic necessity for businesses to initiate ways to effectively acquire and manage varying organizational knowledge, when produced and disseminated all over the organization has the capability to contribute to the firm's value (Choi \& Lee, 2002). Hence, knowledge management (KM) is considered to be an urgent and critical issue, to such an extent that organizations must efficiently manage their knowledge bases and repositories to earn longterm competitive advantage (Alabi \& Leidner, 2001). Knowledge management also enables an organization to gain insight and understanding from its own experience and procedures. But the attention given to Nigeria's KM system has been weak and unstable and has consequently affected its effectiveness and utilization.

Various points has been listed out to be among the contributing factors to the failure of knowledge management in an organization as it has been identified that in the past, knowledge has been managed through human resources and/or information technology divisions and it has not received the direct attention of management that it deserves and needs. This is a major cause of suboptimal performance and is a source of risk as other enabler factors have not been considered. An analysis of KM failures revealed that many organizations who failed did not determine their goals and strategy before implementing KM systems (Rus \& Lindvall, 2002). Some organizations ended up managing documents instead of meaningful knowledge. This is an easy mistake to make, because many tools advertised as KM tools address document management rather than knowledge management (Rus \& Lindvall, 2002).

\section{Objective of the Study}

The objective of the study is directed to:

$>$ investigate the effect of strategic leadership on financial performance;

$>$ determine the impact of organizational culture on financial performance;

$>$ examine the effect of information and communication technology on financial performance;

$>$ assess the impact of human resources practices on financial performance.

\section{Literature Review}

\section{a. Conceptual Analysis}

Knowledge. Knowledge is the result of deriving realities in light of a man's own skill and influenced by the conduct of its proprietor. Learning is built up on the decision, observation and it is fused by convictions, states of mind and practices. It is data prepared in the brains of the people (Alavi and Leidner, 2001). Knowledge is defined as the awareness of what one knows through study, reasoning, experience or association or through various other types of learning (McInerney, 2002). Knowledge is a key competitive strategy that businesses must manage in their quest to achieving sustainable competitive advantage.

Knowledge Management. Knowledge management is the methodology of information creation, endorsement, presentation, spread and appraisal (Bhatt, 2001). Knowledge management deals with philosophy, systems and specific and administrative gadgets, laid out towards making, granting, utilizing information and data inside and around an association (Wong, 2005). Management of knowledge is called as Knowledge-based management. Management of knowledge is about connecting people to people and people to information so that favorable position on opponents can be picked up. Knowledge management is more a human resource administration rather than engineering-based field. 
Nonaka (1998) defined knowledge management as the process of discovering or creating new knowledge and refining existing knowledge. Also, KM is the sharing of knowledge among individuals and across all organizational boundaries (Wong, 2005). The major purpose of KM is to attain superior internal operating performance and efficiencies within an organization (Drucker, 2000).

Enabler Factors of Knowledge Management. Arthur Anderson Business Consulting (2009) believed that leadership, people, corporate culture and information technology are the biggest enablers of knowledge management implementation. According to this research knowledge management enablers are the key factors that determine the effectiveness of knowledge management within an organisation (Yeh, Lai \& Ho, 2006)

Strategic Leadership. Leadership plays a major role in ensuring success in any initiative within an organization. Organizations can not overlook the critical role of leadership in knowledge management. Knowledge management is essential to be guided and supported by the business leadership. Both practitioners and academicians agree that the leadership plays a major role in the creation and management of knowledge in the organisation, therefore the organizational goal of knowledge management for competitive advantage is facilitated by the practices that leadership implements (Singh, 2008). The introduction of a knowledge management program can be a major organisation change and for this reason the involvement of leadership is considered imperious. Leadership should create a climate that encourages the distribution of knowledge, so that people feel safe to contribute in every way, and the contributions are recognized by them. In addition, they should have the will to share and offer their knowledge to others in the organization, to learn constantly, and to seek new ideas and knowledge.

Culture. Although leadership plays a key role in knowledge management effective implementation, the culture factor can be even more important to knowledge management performance incentives. Many researchers and practitioners supported that organizational culture can enable the successful implementation of knowledge management. Culture is important for facilitating sharing, learning, and knowledge creation. In general, culture highly values knowledge, encourages its creation, sharing, application, and promotes open climate for free flow of ideas. The development of such culture is the major challenge for knowledge management efforts. An effective culture for knowledge management consists of norms and practices that promote the transfer of information between employees and across department lines. (Yeh, Lai, \& Ho, 2006). Building an effective culture which people operate in an organisation is a Critical requirement for effective knowledge management (Gupta \& Govindarahan, 2000). Studies conducted to investigate causes of knowledge management initiative failure, have recognised that organisational culture is the main barrier to knowledge management success (Tuggle \& Shaw, 2000).

Information Technology. After strategy, information technology comes into play, holding an important role for knowledge management effectiveness. Technology is a powerful enabler of knowledge management success. It is generally accepted that databases, intranets, knowledge platforms and networks are the main blocks that support knowledge management. It is indisputable that Information Technology is one of the key factors that influence knowledge management implementation. According to American Productivity and Quality Center International Benchmarking Clearinghouse study, the crucial role for information technology lies in its ability to support communication, collaboration, and search for knowledge and information, not static repositories of "best practices" (McCampbell, Clare, \& Gitters, 1999). There is an extensive collection of information technologies such as data warehousing, intranet, internet, which can be implemented and integrated in an organization's technological platform and work together as knowledge management system.

Human Resources. The role of people in knowledge management success is major. People create and share knowledge, and for this reason managing the persons who have the intension to create and share their knowledge is considered very important. Since, people are the exclusive creators of knowledge, Davenport and Volpel (2001) reported "managing knowledge is managing people, and managing people is managing knowledge". The knowledge is hold by an individual, the process of transferring this hidden knowledge to other members within an organization; so as to share, use, and convert it into knowledge is a crucial procedure. Thus, a key factor for an organization to meet success is to support people communicate and share knowledge with others (Nonaka \& Takeuchi, 1995). Szulanski, (1996) stated that organizations should perceive that employees are a vital resource for their organization and to combine the concept of knowledge management into their employee management policy, because it is critical for an employee to be motivated to take part in the obtaining and sharing of knowledge (Wong, 2005). 


\section{Organizational Performance}

Performance within the organization is a persistent subject in the majority of management branches and there is an apprehension toward both instructive persons and additionally rehearsing supervisors. Performance idea has been usually perceived; however, considering performance in examination setting is a testing problem confronted by specialists. Performance of an organization, from conventional perspective is typically alluded to as: Financial performance where spending plans, resources, operations, items, administrations, markets and HR are serious to impact the general primary concern of an association". Monetary results of organizational efficiency are ordinarily connected to authoritative accomplishment (Lee and Kim, 2002). The idea of efficiency has more extensive measurements of clarifications by accentuation on knowledge gained by a firm and efficiency results connected with it, so there is a necessary to carefully manage it (Lee and Kim, 2002).

\section{b. Theoretical Analysis}

Knowledge Management Theory. The main idea of the knowledge-based theory of the firm is that organizations exist in the way that they do because of their ability to manage knowledge more efficiently than is possible under other types of organizational structures. In other words, organizations are social entities that use and store internal knowledge, competencies and capabilities that are vital for the firm's survival, growth and success. The theory assumes that organizations are all heterogeneous knowledge-bearing entities that apply knowledge to the production of their goods and services (Foss, 1996). Firms are able to organize the way they do because they are depositories of productive knowledge. This view stresses that knowledge is the most strategically important resource of the firm. In the KBV, the primary goal of the firm is the application of existing knowledge to the production of goods and services. Knowledge and skills give a firm competitive advantage, because it is through this set of knowledge and skills that a firm is able to innovate new products and processes, or improve existing ones more efficiently and or effectively (Nonaka \& Takeuchi, 1995).

\section{c. Empirical Analysis}

Zaied, Hussein, and Hassan (2013) examined the relationship between knowledge management and organizational development from the perspective of sports and youth department staff. It consisted of a statistical population of all employees of the office of youth and sports in Mazandarian province. It analyzed data using descriptive statistics and inferential statistics (Pearson correlation test and Multivariate Regression). The results indicated that there is a significant relationship between knowledge management and organizational development. It observed that among the four dimensions of knowledge management i.e. knowledge acquisition, knowledge transfer, knowledge utilization, knowledge recording; only there was a relation between the knowledge management utilization and organizational development.

Buheji (2014) conducted a research on Knowledge Management Influence on Government Organisations Competitiveness. To ascertain the relationships between KM and four prevalent organisational development practices. A total of 625 valid responses were collected from top and middle management from 54 government organizations in the Kingdom of Bahrain. The model was statistically tested according to the research hypotheses by regression analysis then Structural Equation Modelling (SEM). Results reveal strong and significant correlations amongst the five prevalent organizational development practices. Even though the holistic influence of the model could not be confirmed, findings show positive KM influence on the remaining organizational development practices, thus KM is an essential factor for government organizations.

Choi (2014) conducted a study titled knowledge management enablers, processes, and organizational performance: an integration and empirical examination. the objective of the study was to identify and examine the effect of knowledge enable factors on organization performance. The research used quantitative data that was derived from a structured questionnaire which was analyzed using regression analysis. The research proposes a model to illustrate the relationship between knowledge management strategies and their creating processes. The model shows that the strategies vary depending on different knowledge creating processes. Result of this study is that in order to manage knowledge effectively, human strategy is more likely to be adopted in the case of the socialization process while system strategy is more likely to be adopted in the case of the combination process.

Olota (2015) did a research on the Impact of Knowledge Management on Entrepreneurship Performance in Nigeria Telecommunication Industry. The study was design to examine the elements of knowledge management in Nigeria Telecommunication industry; a total of 349 out of 375 questionnaires administered were returned. Multi-stage sampling method was used for the selection of the staff of the two companies. The 
techniques employed for data analysis include multiple correlation, descriptive analysis, linear correlation and Multiple Regression. The findings of the study were there existing a Positive correlation exist among most of the element of knowledge management in Nigeria Telecommunication at 0.01 and 0.05 significant level except for search engines and intellectual. The study concluded that since knowledge management has proved to be an important factor and the driving force behind Entrepreneurship performance in Nigeria Telecommunication Industry, the adoption and continued usage should be encouraged.

\section{Methodology}

Descriptive survey research design was adopted for this study; this method was considered appropriate for this study because it will help the researcher to discover relative incidence and distribution on the population. Population of the study comprises of one hundred and twenty (120) employees of Dangote Flourmills, Ilorin a sample size of Ninety-two (92) was determined using Yaro Yamane formulae. Data was gathered using primary source of data, a well-structured five -points scale questionnaire was used as an instrument of data collection. Descriptive statistics of simple percentages, mean would be used while inferential statistics of Multiple Regression Analysis was used to test the formulated hypotheses using STATA 11 data analysis package.

\section{Results and Discussion of Findings}

\section{Test of Hypothesis I}

$\mathbf{H}_{\mathbf{0 1}}$ : Strategic leadership does not have any significant impact on financial performance.

Table 1. Multiple regression analysis showing the impact of strategic leadership on financial performance

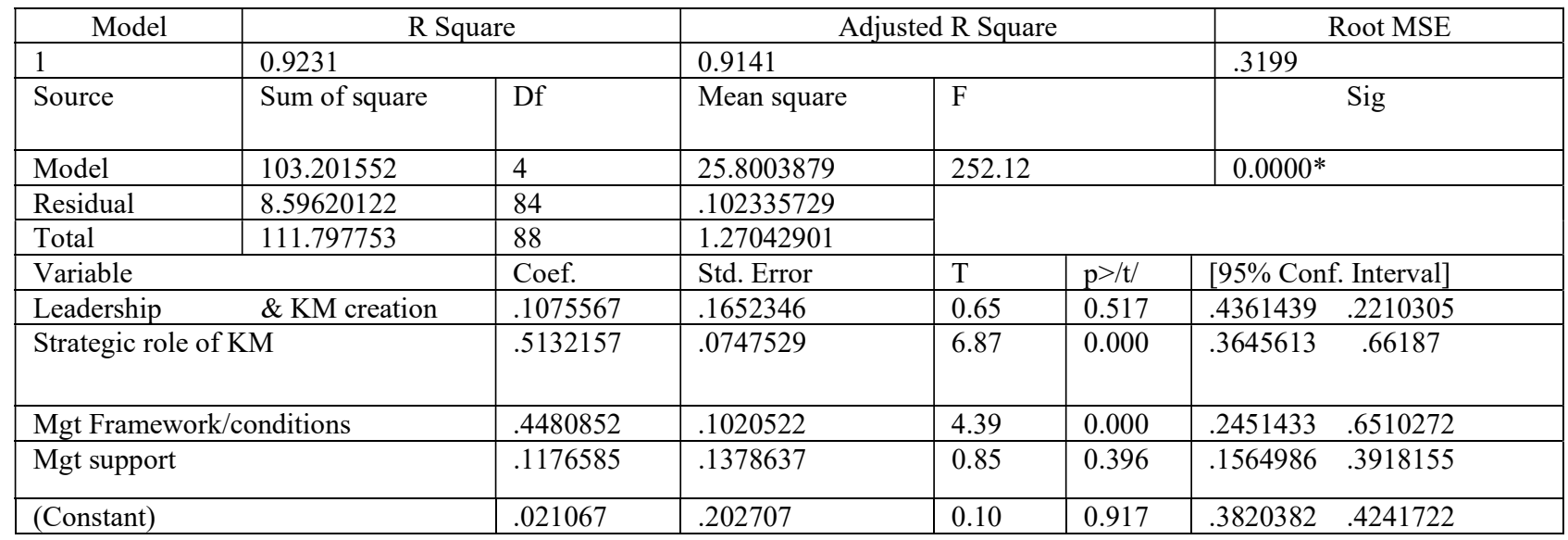

Source: Researcher's Analysis (2019) using STATA version 11. (Statistically significant at 5\%).

The regression analysis results obtained in the evaluation of the impact of strategic leadership on financial performance indicates that the $\mathrm{R}^{2}$ coefficient $(0.9231)$ which is the coefficient of determination indicates that the explanatory variables account for $92 \%$ of the variation of influence that strategic leadership has on financial performance. The adjusted $\mathrm{R}^{2}$ is $91 \%$ with $0.0000 *$ at $5 \%$ of significant. This is an indication that the independent variables in the model jointly and significantly explain the impact of strategic leadership on financial performance. The null hypothesis is rejected and the alternate hypothesis is accepted which states that indeed strategic leadership have significant effect on financial performance. This is consistently in line with previous studies of Zaied, Hussein, and Hassan (2013), Buheji (2014), Choi (2014) and Olota (2015) who concluded that knowledge management have significant influence on organisational performance.

\section{Test of Hypothesis II}

$\mathbf{H}_{\mathbf{0} 2}$ : Organizational culture does not have any significant impact on organizational performance.

Table 2. Multiple regression analysis showing the impact of organization culture on financial performance

\begin{tabular}{|c|c|c|c|c|c|}
\hline Model & \multicolumn{2}{|c|}{ R Square } & \multicolumn{2}{|c|}{ Adjusted R Square } & Root MSE \\
\hline 2 & 0.9623 & & 0.9640 & & .38682 \\
\hline Source & Sum of square & Df & Mean square & $\mathrm{F}$ & Sig \\
\hline
\end{tabular}


Table 2 (cont.). Multiple regression analysis showing the impact of organization culture on financial performance

\begin{tabular}{|c|c|c|c|c|c|c|}
\hline Model & 101.495135 & 4 & 25.3737838 & \multicolumn{2}{|c|}{563.00} & $0.0000 *$ \\
\hline Residual & 3.78576368 & 84 & .045068615 & & & \\
\hline Total & 105.280899 & 88 & 1.19637385 & & & \\
\hline \multicolumn{2}{|l|}{ Variable } & Coef. & Std. Error & $\mathrm{T}$ & $\mathrm{p}>/ \mathrm{t} /$ & [95\% Conf. Interval] \\
\hline \multicolumn{2}{|c|}{ Knowledge sharing } & .1640028 & .0884412 & 0.54 & 0.591 & $.4145788 \quad .2376964$ \\
\hline \multicolumn{2}{|c|}{ Cooperative workforce } & .0706844 & .08269 & 0.85 & 0.395 & .0937537 .2351224 \\
\hline \multicolumn{2}{|c|}{ Teamwork } & .9564109 & .152752 & 6.26 & 0.000 & $.6526469 \quad 1.260175$ \\
\hline \multicolumn{2}{|c|}{ Effective communication } & .063832 & .1000024 & 0.64 & 0.525 & $.1350338 \quad .2626977$ \\
\hline \multicolumn{2}{|c|}{ (Constant) } & .0535334 & .134047 & 0.40 & 0.691 & .3201005 \\
\hline
\end{tabular}

Source: Researcher's Analysis (2019) using STATA version 11. (Statistically significant at 5\%).

The regression analysis results obtained in the evaluation of the impact of organization culture on financial performance indicates that the $\mathrm{R}^{2}$ coefficient $(0.9623)$ which is the coefficient of determination indicates that the explanatory variables account for $96 \%$ of the variation of influence that organization culture has on financial performance. The adjusted $\mathrm{R}^{2}$ is 96 with $0.0000^{*}$ at $5 \%$ of significant. This is an indication that the independent variables in the model jointly and significantly explain the impact of organization culture on financial performance. The null hypothesis is rejected and the alternate hypothesis is accepted which states that indeed organization culture have significant effect on financial performance. This is consistently in line with previous studies of Zaied, Hussein, and Hassan (2013), Buheji (2014), Choi (2014) and Olota (2015) who concluded that knowledge management have significant influence on organisation performance.

\section{Test of Hypothesis III}

$\mathbf{H}_{\mathbf{0}}$ : Information and communication technology does not have any significant impact on organizational performance.

Table 3. Multiple regression analysis showing the impact of information and communication technology on financial performance

\begin{tabular}{|c|c|c|c|c|c|c|}
\hline Model & \multicolumn{2}{|c|}{ R Square } & \multicolumn{3}{|c|}{ Adjusted R Square } & Root MSE \\
\hline 3 & \multicolumn{2}{|l|}{0.8927} & \multicolumn{3}{|l|}{0.8876} & .36384 \\
\hline Source & Sum of square & Df & Mean square & \multicolumn{2}{|l|}{$\mathrm{F}$} & Sig \\
\hline Model & 92.4758862 & 4 & 23.1189716 & \multicolumn{2}{|l|}{174.65} & $0.0000^{*}$ \\
\hline Residual & 11.1196194 & 84 & .132376421 & & & \\
\hline Total & 103.595506 & 88 & 1.17722165 & & & \\
\hline \multicolumn{2}{|l|}{ Variable } & Coef. & Std. Error & $\mathrm{T}$ & $\mathrm{p}>/ \mathrm{t} /$ & [95\% Conf. Interval] \\
\hline \multicolumn{2}{|c|}{ Knowledge Mgt system } & .8249024 & .1483866 & 5.56 & 0.000 & $.5298194 \quad 1.119985$ \\
\hline \multicolumn{2}{|c|}{ Internet \& E-Mail } & .1365187 & .1913802 & 0.71 & 0.478 & $.2440618 \quad .5170992$ \\
\hline \multicolumn{2}{|c|}{ Technology adoption } & .1908075 & .177163 & 1.08 & 0.285 & $.5431156 \quad .1615006$ \\
\hline \multicolumn{2}{|c|}{ Data Warehousing } & .1128849 & .1421702 & 0.79 & 0.429 & $.1698362 \quad .3956059$ \\
\hline \multicolumn{2}{|l|}{ (Constant) } & .1384488 & .2386095 & .0 .58 & 0.563 & .3360525 \\
\hline
\end{tabular}

Source: Researcher's Analysis (2019) using STATA version 11. (Statistically significant at 5\%).

The regression analysis results obtained in the evaluation of the impact of information and communication technology on financial performance indicates that the $\mathrm{R}^{2}$ coefficient $(0.8927)$ which is the coefficient of determination indicates that the explanatory variables account for $89 \%$ of the variation of influence that information and communication technology has on financial performance. The adjusted $\mathrm{R}^{2}$ is $89 \%$ with $0.0000^{*}$ at $5 \%$ of significant. This is an indication that the independent variables in the model jointly and significantly explain the impact of information and communication technology on financial performance. The null hypothesis is rejected, and the alternate hypothesis is accepted which states that indeed information and communication technology have significant effect on financial performance. This is consistently in line with previous studies of Zaied, Hussein, and Hassan (2013), Buheji (2014), Choi (2014) and Olota (2015) who concluded that knowledge management have significant influence on organization performance.

\section{Test of Hypothesis IV}

$\mathbf{H}_{\mathbf{0} 4:}$ Human resources does not have any significant impact on organizational performance. 
Multiple regression analysis showing the impact of effective human resource on financial performance

\begin{tabular}{|c|c|c|c|c|c|c|}
\hline Model & \multicolumn{2}{|c|}{ R Square } & \multicolumn{3}{|c|}{ Adjusted R Square } & Root MSE \\
\hline 4 & \multicolumn{2}{|l|}{0.7592} & \multicolumn{3}{|l|}{0.7478} & .38682 \\
\hline Source & Sum of square & Df & Mean square & \multicolumn{2}{|l|}{$\mathrm{F}$} & Sig \\
\hline Model & 39.6336273 & 4 & 9.90840683 & \multicolumn{2}{|l|}{66.22} & $0.0000^{*}$ \\
\hline Residual & 12.5686199 & 84 & .149626427 & & & \\
\hline Total & 52.2022472 & 88 & .593207354 & & & \\
\hline \multicolumn{2}{|l|}{ Variable } & Coef. & Std. Error & $\mathrm{T}$ & $\mathrm{p}>/ \mathrm{t} /$ & [95\% Conf. Interval] \\
\hline \multicolumn{2}{|l|}{ Meetings } & .1392758 & .1484075 & 0.94 & 0.351 & .43434966 .1557981 \\
\hline \multicolumn{2}{|c|}{ Creativity and Innovation } & $5.00 \mathrm{e}$ & .3051392 & 0.00 & 1.000 & $\begin{array}{ll}-.6066985 & .6066985 \\
\end{array}$ \\
\hline \multicolumn{2}{|c|}{ Reward system } & .7576602 & .2763622 & 2.74 & 0.007 & $.208178 \quad 1.307142$ \\
\hline \multicolumn{2}{|l|}{ Incentives } & 1.768802 & .1691523 & 10.46 & 0.000 & $1.432482 \quad 2.105122$ \\
\hline \multicolumn{2}{|l|}{ (Constant) } & 1.783534 & .1705335 & 10.46 & 0.000 & $1.444409 \quad 2.122658$ \\
\hline
\end{tabular}

Source: Researcher's Analysis (2019) using STATA version 11. (Statistically significant at 5\%).

The regression analysis results obtained in the evaluation of the impact of effective human resource practices on financial performance indicates that the $\mathrm{R}^{2}$ coefficient $(0.7592)$ which is the coefficient of determination indicates that the explanatory variables account for $76 \%$ of the variation of influence that effective human resource practices has on financial performance. The adjusted $\mathrm{R}^{2}$ is $76 \%$ with $0.0000^{*}$ at $5 \%$ of significant. This is an indication that the independent variables in the model jointly and significantly explain the impact of effective human resource on financial performance. The null hypothesis is rejected, and the alternate hypothesis is accepted which states that indeed effective human resource practices have significant effect on financial performance. This is consistently in line with previous studies of Zaied, Hussein, and Hassan (2013), Buheji (2014), Choi (2014) and Olota (2015) who concluded that knowledge management have significant influence on organization performance.

\section{Conclusions}

In today's business environment knowledge management is considered as the main source of competitive advantage for organizations. Knowledge is recognized as a key economic resource and thus organizations should possess the right knowledge in the desired form and content under all circumstances in order to be successful. It is clear that knowledge is an important asset in organizations in the knowledge economy. Knowledge is associated with people, money, leverage, learning, flexibility, power and competitive advantage. Organizations how to give employees the organizational knowledge they need - at the time needed - can position themselves to compete more effectively and succeed much faster. Organizations that harness and manage their intellectual capital can apply that asset to business challenges and opportunities. For knowledge to be of value in organizations it must be focused, current, tested, shared and managed effectively. Knowledge management is seen as a business process, integrating knowledge, people, processes, strategies, techniques and technologies. The management of knowledge involves a systematic approach to nurturing, protecting and exploiting that knowledge, which is important to the success of the organization. Knowledge management helps an organization to gain insight and understanding from its own experience. Knowledge management activities help focus the organization on acquiring, storing and utilizing knowledge for problem solving, dynamic learning, strategic planning and decision-making. Based on the findings of this study, it can be concluded that knowledge management enabler factors have significant effect on financial performance and organization performance as a whole.

\section{Recommendations}

It is noticed that mangers have a key role in facilitating KM. Their role extends from identifying the needed knowledge to being leaders and mentors. It is important for strategic management managers to demonstrate their commitment to KM with resources, action, guidelines, and activities. It is also important for management to support knowledge sharing, learning and other KM desired behaviors. It is also important to have a flexible, well structured, up-to-date knowledge map to pint staff in the direction of the knowledge they seek. It is critical that strategic managers be responsible for motivating, mentoring, and coaching their employees

It is also critical to have an organizational culture that facilitates KM given that organizational culture plays a critical role in facilitating knowledge management. Organization must continually foster a culture that constantly ensures the enshrinement of knowledge management policies. The culture must be one that sees 
$\mathrm{KM}$ as a vital element of business strategy and to recognize knowledge as the basis of a company's competitive position.

The importance of ICT cannot be overemphasized in the $21^{\text {st }}$ century. It is a fundamental and germane enabler of $\mathrm{KM}$ in organizations. Organizations must continually deploy various technologies to enhance communication and facilitate the management of knowledge based on their needs and requirements. It is important that information is available to the right people at the right time. It is important to have organizations' policies, standards, and manuals stored in databases and made available to employees. It is also important to document, and store procedures and lessons learned from experience in databases. In addition, it is important to utilize IT such as massaging systems and conference tools, to allow effective communication across boundaries and time zones.

It is also critical to have an organizational culture that facilitates $\mathrm{KM}$ given that organizational culture plays a critical role in facilitating knowledge management. Organization must continually foster a culture that constantly ensures the enshrinement of knowledge management policies. The culture must be one that sees $\mathrm{KM}$ as a vital element of business strategy and to recognize knowledge as the basis of a company's competitive position.

\section{References}

1. Alavi, M. and Leidner, D.E. (2001). Review: knowledge management and knowledge management systems: conceptual foundations and research issues, MIS Quarterly, 1, 107 - 136. https://doi.org/10.1348/01446660016411298.

2. Arthur Anderson and The APQC (2009). The Knowledge Management Assessment Tool. Arthur Anderson and The American Productivity \& Quality Center. Available at: https://www.researchgate.net/publication

3. Bhatt, G.D. (2001). Knowledge management in organizations: examining the interaction between technologies, techniques, and people, Journal of Knowledge Management, 5(1), 68-75. https://www.researchgate.net/publication/33189455822.

4. Buheji, M (2014). Practical Approach for establishing Knowledge Management Strategies for Governmental Institutions in GCC, 37th IFTDO World Conference. Knowledge Management in Training and Development, 3-6 March - Dubai. Available at: https://www.scribd.com/document

5. Choi, B. and Lee, H. (2002) Knowledge management strategy and its link to knowledge creation process. Expert Systems with Applications, 23(3), 173-187. Available at: https://www.academia.edu.

6. Choi, B (2014). Knowledge Management Enablers, Processes, and Organizational Performance: An Integration and Empirical Examination. Unpublished dissertation, Korea Advanced Institute of Science and Technology. Available at: https://www.academia.edu.

7. Davenport, T.H. and S.C. Volpel, (2001). The rise of knowledge towards attention management, Journal of Knowledge Management, 5 (3), 212-21. Available at: https://EconPapers.repec.org/RePEc:eco:journ.

8. Davenport and Prusak (2007), Working knowledge: how organizations manage what they know, Harvard Business School Press, Boston, MA. Available at: https://www.koganpage.com.

9. Drucker, P. (2000). Knowledge-worker productivity: The biggest challenge. In J. W. Cortada, \& J. Everard, (Eds.), Library Management, 22(6/7), 297 - 302. DOI: 10.11634/216796061302415

10. Finn, B (2015). An Investigation into the Impact of Knowledge Management in Improving Organisational Effectiveness and Generating Sustained Competitive Advantage Unpublished Masters Thesis, Dublin Business School and Liverpool John Moores University. Available at: https:/www.academia.edu/

11. Foss, N. J. (1996). More critical comments on knowledge-based theories of the firm.Organization Science, 7(5), 519-523. Available at: https://www.academia.edu/1611986.

12. Gupta, A. K., and Govindarajan, V. (2000) Knowledge management's social dimension: lessons from Nucor steel. Sloan Management Review (Fall 2000), 71-80. Available at: https://www.academia.edu/

13. Lee, J.H and Kim, Y.G. (2002) Effects of managerial drivers and climate maturity on knowledge management performance: empirical validation. Proceedings of Pacific Asia Conference on Information Systems. 1(3), 1097-1111. Available at: https://www.researchgate.net/publication/310455811.

14. McCampbell, A., L.M Clare, and S.H Gitters (1999). Knowledge management: the new challenge for the $21 \mathrm{st}$ century, Journal of Knowledge Management, 3 (3), 172-179. https://doi.org/10.1348/014466671229715.

15. Marwick, A. D. (2001). Knowledge management technology',IBM Systems Journal, 40(4), 814-830. Available at: https://EconPapers.repec.org/RePEc:eco:journ. 
16. McDermott, R. (2002). Measuring the impact of communities: How to draw meaning from measures of communities of practice', Knowledge Management Review, 5(2), 26-29. Available at: https://www.researchgate.net/publication/482219603.

17. McInerney, C. (2002). Knowledge management and the dynamic nature of knowledge, Journal of the American society for information science and technology 53(12), 1009. DOI: 10.22634/21679606147118

18. Mohamed, M., M. Stankosky, and A. Murray (2006). Knowledge management and information technology: can they work in perfect harmony? Journal of Knowledge Management, 10 (3), 103-116. https://doi.org/10.1348/014466600164426

19. Nonaka, I., \& Takeuchi, H. (1995). The knowledge-creating company: How Japanese companies create the dynamics of innovation. New York: Oxford University Press. Available at: https://www.koganpage.com.Nonaka, I. (1998). Organising innovation as a knowledge creation process. Working Paper No. OBIR-41. California: Univ. Press. Available at: https://pdfs.semanticscholar.org/

20. Nonaka, I., \& Takeuchi, H. (1995). The knowledge-creating company: How Japanese companies create the dynamics of innovation. New York: Oxford University Press. Available at: https://www.scribd.com/document

21. Olota, Y. (2015). Impact of Knowledge Management on Intraprenuership Performance In Nigeria Telecommunication Industry. Unpublished Masters dissertation, University of Ilorin. Available at: https://www.academia.edu.

22. Rus and Lindvall (2002). Knowledge management in software engineering, IEEE Software, May/June, 26-38. Available at: https://www.academia.edu.

23. Szulanski, G. (1996). Exploring internal stickiness: Impediments to the transfer of best practices within the firm, Strategic Management Journal, 17, 27-43. Available at: https://www.academia.edu.

24. Tseng, S. (2008) The correlation between organizational culture and knowledge conversion on corporate performance, Journal of Knowledge Management. 14(2), 269-284. Available at: https://EconPapers.repec.org/RePEc:eco:journ.

25. Tuggle, F.D and N.C Shaw (2000). The effect of organizational culture on the implementation of knowledge management, Orlando: Florida Artificial intelligence Research Symposioum (FLAIRS), FL. Available at: https://www.scribd.com/document

26. Wong, K. (2005). Critical success factors for implementing knowledge management in small and medium enterprises, Industrial Management \& Data Systems, 105 (3), 261-279. DOI: 10.22634/21679606147118

27. Yeh, Y., Lai, S. and Ho, C. (2006) Knowledge management enablers: a case study, Industrial Management \& Data Systems, 106(6), 793-810. Available at: https://www.researchgate.net/publication

28. Zaied, A.N.H., Hussein, G.S. and Hassan M.M. (2013). The Role of Knowledge Management in Enhancing Organizational Performance. I.J. Information Engineering and Electronic Business, 5, 27-35. Available at: https://EconPapers.repec.org/RePEc:eco:journ. 